\title{
Correlation between Pharyngeal Airway Space and Craniofacial Morphology - A Cephalometric Study
}

\author{
Alok Kumar ${ }^{1}$,Mrinal Kr Nandi ${ }^{2}$ \\ ${ }^{I}$ Associate Professor, Department of Orthodontics \& Dentofacial Orthopaedics, Awadh Dental College \& \\ Hospital, Jamshedpur, India. \\ ${ }^{2}$ Post Graduate Student, Department of Orthodontics \& Dentofacial Orthopaedics, Awadh Dental College \& \\ Hospital, Jamshedpur, India.
}

\begin{abstract}
:
Introduction: The aim of the present study was to evaluate the effect of craniofacial morphology on pharyngeal airway space (PAS) in individuals with normal sagittal skeletal pattern.

Materials and Methods: A total of 30 adult female patients with skeletal Class I jaw relationship were included in the study. Lateral cephalograms were obtained and hand traced. Various soft and hard tissue points identified and linear and angular measurements carried out to evaluate the pharyngeal airway space. The data thus collected were subjected to statistical analysis.

Result: The linear variables LAFH (lower anterior face height) and $\mathrm{Na}-\mathrm{Se}-\mathrm{Ba}$ (cranial base length) did not show statistically significant correlation with PAS. Among angular variables, although MPA (mandibular plane angle) showed a negative correlation however it was statistically insignificant. Other angular variables like Na$\mathrm{Se}-\mathrm{Ba}$ angle (cranial base angle), SNA and SNB did not correlate with the posterior airway space.

Conclusion: The study concluded that craniofacial morphology does not have any significant bearing on the pharyngeal airway space. At best its role in pharyngeal airway discrepancies can be defined as secondary and contributory.
\end{abstract}

Keywords: Pharyngeal Airway Space, Craniofacial Morphology, Skeletal Class I

\section{Introduction}

The pharyngeal airway space is an organ composed of 20 or more muscles that are attached proximally to skeletal structures and whose size and form are affected by the developing craniofacialskeleton. ${ }^{1-2}$ It is composed of three parts: the nasopharynx, oropharynx, and hypopharynx.Respiratory function and upper airway morphology are greatly relevant to orthodontic diagnosis andtreatment planning as altered breathing function could influence facial growth and morphology. ${ }^{3}$ More importantly, breathing disturbances could lead to increased morbidity and mortality in a condition like obstructive sleep apnoea (OSA). ${ }^{4}$ Many reports have demonstrated a relationship between various malocclusion patternsand variations in the size and form of the oropharyngeal airway.The relationship between craniofacial morphology and respiratory function has been the focus ofinvestigation since the 19th century. ${ }^{8}$ A number of studies have been published on the relationshipsbetween the pharyngeal airway and the facial pattern. ${ }^{9-14}$ Several of these studies have found that pharyngeal airway dimensions and/or volumes are affected by sagittal skeletal patterns. ${ }^{10-14}$ Thus,it can be assumed that the findings reported previously might be affected by sagittal skeletal pattern distribution of the patients.

The aim of the present study was to evaluate the effect of craniofacial morphology on pharyngeal airway space in individuals with normal sagittal skeletal pattern.

\section{Materials \& Method}

The subjects comprised of 30 adult female patients having skeletal Class I Jaw relationship. The mean age of the group was 22 years, with a range of 18 years to 32 years. They were selected from the records of patients maintained at Department of Orthodontics, Awadh Dental College \& Hospital Jamshedpur.

\section{Criteria for selection of sample:}

1. Adult female patients having skeletal Class I jaw relationship, with ANB angle more than $0^{0}$ but less than $4^{0}$ and Witt's appraisal showing AO coinciding with BO.

2. Subject with craniofacial anomalies including cleft lip and palate and gross facial asymmetries were excluded from the study.

3. Subjects with previous history of Orthodontic treatment or Orthognathic surgery were also excluded from the study. 


\section{Method of Study}

Over the years pharyngeal airway space has been studied by various techniques. The most common among them being cephalometry, endoscopic examination ${ }^{15}$, computed tomographic (CT) scan ${ }^{16}$, magnetic resonance (MR) scans ${ }^{17}$ and acoustic reflection techniques. ${ }^{18}$

Each method has its own advantages and disadvantages. The cephalometric analysis of the airway permits precise measurement to be taken in the sagittal plane at anatomically well-defined homologous locations but does not provide transverse dimension of the airway. In spite of the obvious limitations of cephalometry it still remains the most popular technique in the evaluation of posterior airway space because of its easy access, low cost and minimal radiation. ${ }^{19}$

In the present study lateral cephalograms of selected cases were obtained. The following criteria's were observed when exposing the film. ${ }^{20}$

1. The distance from the focus to the median plane was kept at $180 \mathrm{cms}$ and the median plane to film distance at $10 \mathrm{cms}$. The enlargement if any was not corrected.

2. The subjects were seated with median plane parallel to the film with maximum inter-cuspation of the teeth and lips in its natural relaxed position.

3. Bilateral ear rods were gently inserted into the external part of the auditory canal to stabilize the head posture during exposure.

The cephalograms obtained were hand traced; various soft and hard tissue points identified and linear and angular measurements were carried out to evaluate the airway changes. The reference points and lines used in the analysis are as described in previous papers by Lyberg et al (1989) and Krogstad et al (2000). ${ }^{21-22}$. The various linear and angular measurements carried out in the study are as per Tables $1 \& 2$ and the same has been illustrated in Figures $1 \& 2$.

\section{Method Error}

To reduce the method error in defining the measuring points and reference structures, all radiographs were analysed twice by the same investigator with a two week interval between the recordings. The mean value of the two recording was used as final measuring value. Linear measurements were made to the nearest $0.5 \mathrm{~mm}$ and the angular measurements to the nearest 0.5 degrees. The linear roentgenographic enlargement of $7 \%$ was not corrected.

\section{Statistical Analysis}

The data collected was entered into Microsoft excel spreadsheet and analysed using IBM SPSS Statistics, Version 22(Armonk, NY: IBM Corp). Descriptive data were presented in the form of mean and standard deviation. Pearsons correlation test was used to test the Correlation between craniofacial morphology and pharyngeal air way space at different levels of pharynx. $\mathrm{P}$ value $<0.05$ was considered as statistically significant.

\section{Result}

Table 3 presents the data of different variables used in this study along with their mean and standard deviation. Table 4 presents the correlation of different linear and angular variables to the pharyngeal airway space at different levels of pharynx.

\section{Linear Variables}

The lower anterior face height (LAFH) showed a mild negative correlation to pharyngeal airway space, however it was statistically non-significant. The cranial base length (Na-Se-Ba) did not show any significant correlation with pharyngeal airway space. $(\mathrm{p}>0.05$, Table 4)

\section{Angular Variables}

The mandibular plane angle (MPA) showed a mild negative correlation with the airway space however, statistically it was non-significant. The cranial base angle (Na-Se-Ba) did not show any correlation with the airway space. SNA and SNB values showed a mild positive correlation to pharyngeal airway space however they also were statistically non-significant. ( $p>0.05$, Table 4$)$

\section{Discussion}

Abnormal development of the upper airway is related to airway constriction, and the relationship between reduced respiratory function and craniofacial growth has long been of interest to orthodontists. ${ }^{5,23}$ Different aspects of craniofacial morphology can affect both upper as well as the lower airway and therefore in this study we have evaluated the pharyngeal airway space at four different levels. 
ANB angle is not a very reliable indicator of skeletal jaw relationship, as it is affected by changes in the position of nasion point, vertical rotation of the jaws, anteroposterior position of the Nasion, and vertical distance between point $\mathrm{A}$ and point $\mathrm{B}$. It has been suggested that the orthodontic diagnosis should be based on more than one anteroposterior parameter. ${ }^{24}$ Therefore in the present study in addition to ANB angle, Witt's appraisal was also considered while selecting the sample.

In our study, the cranial base length $(\mathrm{Na}-\mathrm{Ba})$ and the cranial base angle (Na-Se-Ba) did not show any statistically significant correlation with the pharyngeal airway space which is unlike an earlier study carried out by Trenouth \& Timms which showed a significant positive correlation between cranial base angle and pharyngeal airway space. ${ }^{25}$ This could possibly attributed to sample of the present study which was restricted to skeletal Class I jaw relationship.

A mild positive correlation was seen between SNA \& SNB values and the pharyngeal airway space however it was statistically insignificant. This finding is in accordance with earlier studies carried out by Claudino et $\mathrm{al}^{14}$ and Hong et al. ${ }^{26}$ Celikoglu et al conducted a study and found a negative correlation between the growth pattern of the individual and the pharyngeal airway dimensions. ${ }^{27}$ In the present study although the lower anterior face height (LAFH) and the mandibular plane angle (MPA) both showed a mild negative correlation, it was statistically insignificant.

In this study, a very weak influence of craniofacial morphology was found on the oropharyngeal dimension as the airway did not show any statistically significant correlation with any of the craniofacial morphology parameters. This is in accordance with other studies, which have reported either a weak or insignificant correlation between craniofacial morphology and pharyngeal airway space. ${ }^{12,25,28-30}$

\section{Conclusion}

Craniofacial morphology has often been attributed as one of the important factors affecting pharyngeal airway space. However in the present study we did not find any significant correlation between the two. At best it can play a secondary \& contributory role in airway discrepancies.

\section{References}

[1]. Dunn GF, Green LJ, Cunat JJ. Relationships between variation of mandibular morphology and variation of nasopharyngeal airway size in monozygotic twins.Angle Orthod. 1973;43:129-135.

[2]. Ricketts RM. Respiratory obstruction syndrome. Am JOrthod. 1968;54:495-507.

[3]. Solow B, Siersbaek-Nielsen S, Greve E. Airway adequacy, head posture, and craniofacial morphology. Am J Orthod. 1984;86:214223.

[4]. Banno K, Kryger MH. Sleep apnea: clinical investigations in humans. Sleep Med. 2007;8:400-426

[5]. Iwasaki T, Hayasaki H, Takemoto Y, Kanomi R, Yamasaki Y. Oropharyngeal airway in children with Class III malocclusion evaluated by cone-beam computed tomography. Am J Orthod Dentofacial Orthop. 2009;136:318.e311-319.

[6]. Lee YS, Kim JC. A cephalometric study on the airway size according to the types of the malocclusion. Korean J Orthod.1995;25:19-29.

[7]. Joseph AA, Elbaum J, Cisneros GJ, Eisig SB. A cephalometric comparative study of the soft tissue airway dimensions in persons with hyperdivergent and normodivergent facial patterns. J Oral Maxillofac Surg. 1998;56:135-139.

[8]. Meyer C. On adenoid vegatation in the naso-pharyngeal cavity: their pathology, diagnosis and treatment. Med Chir Trans. 1872;53:191-215

[9]. McNamara JA. Influence of respiratory pattern on craniofacial growth. Angle Orthod. 1981;51:269-300.

[10]. Kim YJ, Hong JS, Hwang YI, Park YH. Three-dimensional analysis of pharyngeal airway in preadolescent children with different anteroposterior skeletal patterns.Am J Orthod Dentofacial Orthop. 2010;137:e301-e311.

[11]. El H, Palomo JM. An airway study of different maxillary and mandibular sagittal positions. Eur J Orthod. 2013;35: 262-270.

[12]. El H, Palomo JM. Airway volume for different dentofacial skeletal patterns.Am J Orthod Dentofacial Orthop. 2011;139:e511-e521

[13]. Alves M Jr, Franzotti ES, Baratieri C, Nunes LK, Nojima LI, Ruellas AC. Evaluation of pharyngeal airway space amongst different skeletal patterns. Int J Oral Maxillofac Surg. 2012;41:814-819.

[14]. Claudino LV, Mattos CT, Ruellas AC, Sant' Anna EF.Pharyngeal airway characterization in adolescents related to facial skeletal pattern: a preliminary study. Am J Orthod Dentofacial Orthop. 2013;143:799-809.

[15]. Borowiecki B, Pollak CP, Weitzman ED, Rakoff S, Imperato J. Fibro-optic study of pharyngeal airway during sleep in patients with hypersomnia obstructive sleep-apneasyndrome.Laryngoscope 1978;88(8):1310-13

[16]. Lowe AA, Gionhaku N, Takeuchi K, FleethamJA.Three-dimensional CT reconstructions of tongue and airway in adult subjects with obstructive sleep apnea.Am J Orthod Dentofacial Orthop 1986;90(5):364-74

[17]. Ryan CF, Lowe AA, Li D, FleethamJA.Magnetic resonance imaging of the upper airway in obstructive sleep apnea before and after chronic nasal continuous positive airway pressure therapy.1991;144(4):939-44

[18]. Katz I, Stradling J, Slutsky AS, Zamel N, Hoffstein V. Do patients with obstructive sleep apnea have thick necks? Am Rev RespirDis.1990;141(5):1228-31

[19]. Lowe AA, Santamaria JD, Fleetham JA, Price C. Facialmorphology and obstructive sleep apnea Am J Orthod Dentofacial Orthop. 1986;90(6):484-91

[20]. Achilleos S, Krogstad O and Lyberg T. Surgical mandibular advancement and changes in uvuloglossopharyngeal morphology and head posture : a short and long term cephalometric study in males. European Journal of Orthodontics 2000;22: 367-381.

[21]. Lyberg T, Krogstad O, Djupesland G. Cephalometric analysis in patients with obstructive sleep apnoea syndrome. I. Skeletal morphology. J Laryngol Otol. 1989 Mar;103(3):287-92.

[22]. Lyberg T, Krogstad O, Djupesland G. Cephalometric analysis in patients with obstructive sleep apnoea syndrome: II. Soft tissue morphology.JLaryngol Otol. 1989 Mar;103(3):293-7. 
[23]. Kim YJ, Bok GS, Lee KH, Hwang YI, Park YH. The relationship between upper airway width and facial growth changes in orthodontic treatment of growing children. Korean J Orthod. 2009;39:168-176.

[24]. Ferrario VF, Sforza C, Miani A Jr., Tartaglia GM. The use of linear and angular measurements of maxillo-mandibular anteroposterior discrepancies.Clin Orthod Res 1999;2:34-41.

[25]. Trenouth MJ, Timms DJ. Relationship of the functional oropharynx to craniofacial morphology. Angle Orthod 1999;69:419-23.

[26]. Hong JS, Oh KM, Kim BR, Kim YJ, Park YH. Three-dimensional analysis of pharyngeal airway volume in adults with anterior position of the mandible. Am J Orthod Dentofacial Orthop 2011;140:e161-9

[27]. Celikoglu $\mathbf{M}^{1}$, Bayram M, Sekerci AE, Buyuk SK, Toy E Comparison of pharyngeal airway volume among different vertical skeletal patterns: a cone-beam computed tomography study ; Angle Orthod. 2014 Sep;84(5):782-7. doi: 10.2319/101013-748.1. Epub 2014 Mar 4.

[28]. Abu Allhaija ES, Al-KhateebSN.Uvulo-glosso-pharyngeal dimensions in different anteroposterior skeletal patterns. Angle Orthod. 2005;75:1012-1018

[29]. Grauer D, Cevidanes LS, Styner MA, Ackerman JL, Proffit WR. Pharyngeal airway volume and shape from cone-beam computed tomography: relationship to facial morphology.Am J Orthod Dentofacial Orthop. 2009;136:805-814.

[30]. Oh KM, Hong JS, Kim YJ, Cevidanes LS, Park YH. Three dimensional analysis of pharyngeal airway form in children with anteroposterior facial patterns.Angle Orthod. 2011;81:1075-1082.

Table 1:Linear Variables

\begin{tabular}{|c|l|}
\hline Variables & \multicolumn{1}{c|}{ Definitions } \\
\hline S-N & $\begin{array}{l}\text { It is the distance between Sella point (S) and } \\
\text { Nasion point (Na), determining the extension of } \\
\text { anterior cranial base. }\end{array}$ \\
\hline N-S-Ba & $\begin{array}{l}\text { It is the distance between Nasion to Sella and from } \\
\text { Sella to Basion. It determines the total length of } \\
\text { cranial base. }\end{array}$ \\
\hline Na-Me & $\begin{array}{l}\text { It is the distance measured from Nasion to Menton } \\
\text { perpendicular to the maxillary plane(ANS-PNS).It } \\
\text { represents the lower anterior facial height. }\end{array}$ \\
\hline Pm-UPW & $\begin{array}{l}\text { The distance from Posterior Nasal Spine (PNS) to } \\
\text { Upper Pharyngeal Wall (UPW), measured parallel } \\
\text { to SN plane and representing the naso-pharyngeal } \\
\text { airway space. }\end{array}$ \\
\hline U-MPW & $\begin{array}{l}\text { The distance from tip of uvula (U) to middle } \\
\text { pharyngeal wall (MPW), parallel to SN plane, } \\
\text { representing the oro-pharyngeal airway space. }\end{array}$ \\
\hline PASmin & $\begin{array}{l}\text { The distance from vallecula (V) to lower } \\
\text { pharyngeal wall (LPW), parallel to SN plane, } \\
\text { representing the hypo-pharyngeal airway space. }\end{array}$ \\
\hline $\begin{array}{l}\text { The minimal distance between the base of tongue } \\
\text { and the posterior pharyngeal wall, representing the } \\
\text { minimum pharyngeal airway space. }\end{array}$ \\
\hline
\end{tabular}

Table 2: Angular Variables

\begin{tabular}{|c|l|}
\hline $\begin{array}{c}\text { Variables } \\
\text { (cranial base } \\
\text { angle) }\end{array}$ & $\begin{array}{l}\text { Angle between nasion-sella plane and sella-basion plane, } \\
\text { depicting the flexure of anterior and posterior cranial } \\
\text { bases }\end{array}$ \\
\hline SNA angle & $\begin{array}{l}\text { Angle between nasion-sella plane and nasion - point A } \\
\text { line, shows the relative position of maxilla to anterior } \\
\text { cranial base }\end{array}$ \\
\hline SNB angle & $\begin{array}{l}\text { Angle between nasion-sella plane and nasion - point B } \\
\text { line, shows the relative position of mandible to the } \\
\text { anterior cranial base. }\end{array}$ \\
\hline ANB angle & $\begin{array}{l}\text { Angle between nasion-point A line and nasion - point B } \\
\text { line, shows the relative positioning of mandible to } \\
\text { maxilla }\end{array}$ \\
\hline $\begin{array}{c}\text { MPA } \\
\text { Plane Angle) }\end{array}$ & $\begin{array}{l}\text { Angle between nasion-sella line and mandibular } \\
\text { plane(tangent to lower border of mandible), shows the } \\
\text { growth pattern of the individual }\end{array}$ \\
\hline
\end{tabular}


Table 3:- Linear and angular measurement of variables with their standard deviation.

\begin{tabular}{|c|c|c|c|c|}
\hline & Mean & Std. Deviation & Minimum & Maximum \\
\hline MPA (degrees) & 33.17 & 7.03 & 19 & 47 \\
\hline CB angle (degrees) & 129.27 & 4.57 & 120 & 139 \\
\hline CB length (mm) & 112.43 & 3.88 & 107 & 126 \\
\hline LAFH (mm) & 64.23 & 6.14 & 52 & 76 \\
\hline PM-UPW (mm) & 26.27 & 2.24 & 21 & 30 \\
\hline U-MPW (mm) & 10.13 & 2.99 & 6 & 16 \\
\hline V-LPW (mm) & 14.6 & 3.91 & 6 & 22 \\
\hline PASmin (mm) & 6.23 & 2.21 & 3 & 10 \\
\hline SNA (degrees) & 82.37 & 4.29 & 74 & 93 \\
\hline SNB (degrees) & 79.40 & 4.03 & 72 & 90 \\
\hline ANB (degrees) & 2.97 & 0.93 & 2 & 4 \\
\hline Age (years) & 22.10 & 3.41 & 18 & 32 \\
\hline \multicolumn{2}{|r|}{}
\end{tabular}

Table 4:- Correlation between craniofacial morphology and pharyngeal air way space at different levels of pharynx

\begin{tabular}{|c|c|c|c|c|c|}
\hline \multirow{2}{*}{ MPA } & r & PM-UPW & U-MPW & V-LPW & PAS \\
\cline { 2 - 6 } & p-value & $0.88(\mathrm{NS})$ & $0.15(\mathrm{NS})$ & $0.15(\mathrm{NS})$ & $0.23(\mathrm{NS})$ \\
\hline \multirow{2}{*}{ CB_angle } & $\mathbf{r}$ & 0.22 & 0.04 & -0.09 & -0.18 \\
\cline { 2 - 6 } & p-value & $0.25(\mathrm{NS})$ & $0.85(\mathrm{NS})$ & $0.63(\mathrm{NS})$ & $0.34(\mathrm{NS})$ \\
\hline \multirow{2}{*}{ CB_length } & $\mathbf{r}$ & -0.19 & 0.10 & 0.01 & -0.01 \\
\cline { 2 - 6 } & $\mathbf{p}$-value & $0.32(\mathrm{NS})$ & $0.60(\mathrm{NS})$ & $0.98(\mathrm{NS})$ & $0.97(\mathrm{NS})$ \\
\hline \multirow{2}{*}{ LAFH } & $\mathbf{r}$ & 0.05 & -0.18 & -0.19 & -0.07 \\
\cline { 2 - 6 } & $\mathbf{p}$-value & $0.81(\mathrm{NS})$ & $0.33(\mathrm{NS})$ & $0.31(\mathrm{NS})$ & $0.73(\mathrm{NS})$ \\
\hline \multirow{2}{*}{ SNA } & $\mathbf{r}$ & 0.28 & 0.11 & 0.03 & 0.18 \\
\cline { 2 - 6 } & $\mathbf{p}$-value & $0.14(\mathrm{NS})$ & $0.56(\mathrm{NS})$ & $0.87(\mathrm{NS})$ & $0.35(\mathrm{NS})$ \\
\hline \multirow{2}{*}{ SNB } & $\mathbf{r}$ & 0.22 & 0.11 & 0.05 & 0.23 \\
\cline { 2 - 6 } & $\mathbf{p}$-value & $0.25(\mathrm{NS})$ & $0.55(\mathrm{NS})$ & $0.79(\mathrm{NS})$ & $0.23(\mathrm{NS})$ \\
\hline
\end{tabular}

Pearson's correlation test

$\mathrm{p}<0.05$ statistically significant, $\mathrm{p}>0.05$ Non significant, NS

\section{Legend for Figure 1:}

1-SN plane, 2- Sella to Basion line, 3- FH plane, 4- PNS to UPW (upper pharyngeal wall), 5- U (tip of uvula) to middle pharyngeal wall (MPW), 6- PASmin (Minimum distance between base of tongue and post pharyngeal wall, 7- V(Vallecula) to lower pharyngeal wall (LPW), 8- Mandibular Plane, 9- Lower face height Na-Me

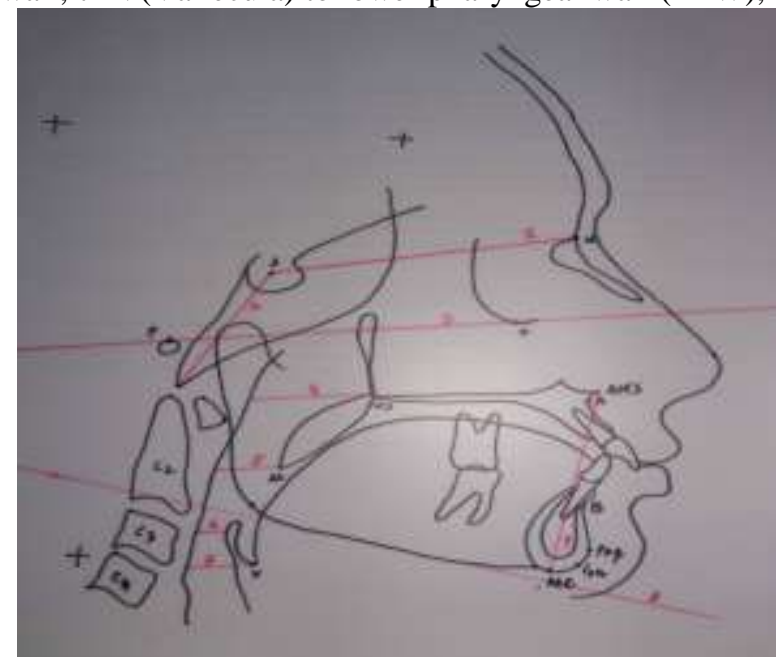

Fig.1

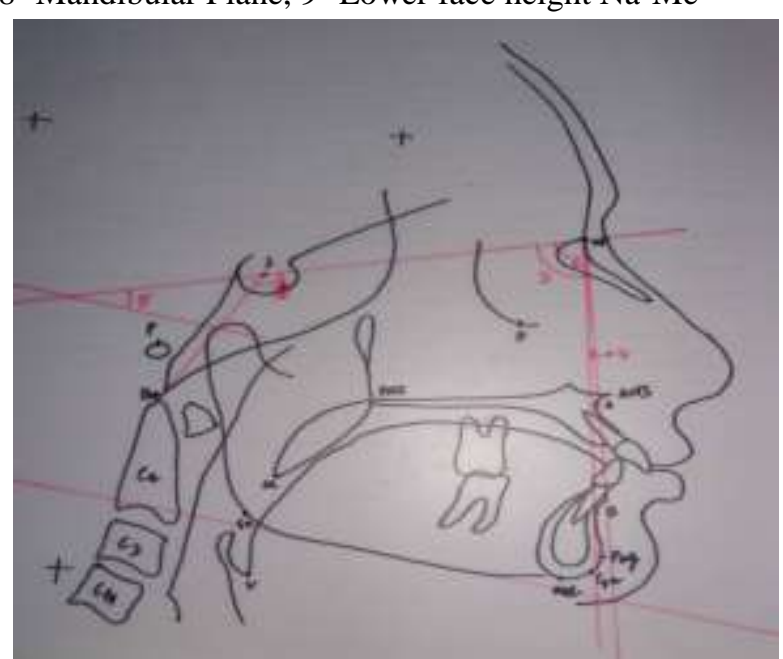

Fig.2

Legend for Figure 2:

1-Cranial Base Angle (NSBa), 2- SNA Angle, 3- SNB Angle, 4- ANB Angle, 5- Mandibular Plane Angle 